\title{
The Next Giant Leap: NASA's Ares Launch Vehicles Overview
}

\author{
Stephen A. Cook \\ Teresa Vanhooser \\ Ares Projects Office \\ Marshall Space Flight Center \\ Huntsville, AL 35812 \\ 256-544-4918 \\ stephen.cook@nasa.gov
}

\begin{abstract}
The National Aeronautics and Space Administration (NASA)'s Constellation Program is developing new launch vehicles (Ares) and spacecraft (Orion) to send astronauts to the Moon, Mars, and beyond. This paper presents plans, projections, and progress toward fielding the Ares I and Ares V vehicles, and the Ares I-X test flight in 2009. NASA is building on both new research and aeronautical capabilities, as well as lessons learned from almost 50 years of aerospace experience. The Ares Projects Office (APO) completed the Ares I System Requirements Review (SRR) in 2006 and the System Definition Review in autumn 2007; and will focus on the Preliminary Design Review in 2008. Ares I is currently being refined to meet safety, operability, reliability, and affordability goals. The Ares team is simultaneously testing Ares I elements and building hardware for Ares I-X, while the Ares V is in the early design stage, with the team validating requirements and ensuring commonality with Ares I. Ares I and V are key to opening the space frontier for peaceful endeavors. ${ }^{12}$
\end{abstract}

\section{TABLE OF CONTENTS}

1. ARES PROJECT INTRODUCTION..............................1

2. TEChNICAL PROGRESS ..........................................2

3. Programmatic Progress...................................6

REFERENCES ..............................................................7

BIOGRAPHIES .........................................................7

\section{Ares Project Introduction}

\section{Program and Vehicle Background}

The next chapter in NASA's history also promises to write the next chapter in America's history, as the Agency makes measurable strides toward developing new space transportation capabilities. Since 2004, NASA has been designing and building a new generation of launch vehicles. Ultimately, it is those vehicles that will enable human exploration of the Moon, Mars, and other destinations in the solar system.

For the Ares launch vehicles, NASA is building on legacy aerospace hardware, coupled with unparalleled aeronautical capabilities, and almost 50 years of experience and lessons

\footnotetext{
${ }^{1}$ U.S. Government work not protected by U.S. copyright.

2 IEEEAC paper \#1555, Version 5, Updated December 31, 2007
}

learned from the Apollo Saturn, Space Shuttle, and commercial launch vehicle programs.

The Exploration Systems Architecture Study (ESAS), completed in 2005, established the requirements (including design reference missions) for both the launch vehicles and the spacecraft necessary to fulfill NASA's exploration mission [1]. Since that Study concluded, the team has performed extensive vehicle analyses, which have refined the original recommendations made by the ESAS and subsequently resulted in hardware commonality decisions to reduce technical, schedule, and budget risk.

Following the Global Exploration Strategy [2] and based on the ESAS recommendations, NASA will retire the Space Shuttle in 2010 and replace it with safe, reliable, and costeffective space transportation systems for crew and cargo travel to the International Space Station (ISS), Moon, Mars, and beyond. The Ares I crew launch vehicle, shown in Figure 1, which lofts the Orion crew exploration vehicle into orbit next decade, will use an in-line configuration for improved crew safety. The first stage comprises a Space Shuttle legacy 5-segment Reusable Solid Rocket Booster (RSRB), while the new upper stage is powered by a J-2X engine, an evolution from the J-2 engine used to power the upper stages of the Apollo Program's Saturn IB and Saturn V.

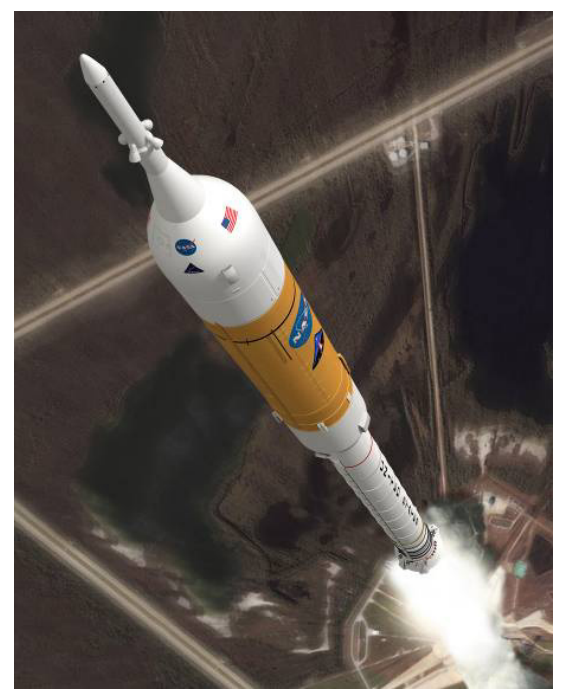

Figure 1 - Ares I Crew Launch Vehicle. 
The heavy-lift Ares V cargo launch vehicle, seen in Figure 2, also builds on legacy hardware, consisting of two RSRBs and a Saturn-class core propulsion stage with five expendable RS-68 engines. Late next decade, the Ares V Earth departure stage, also powered by the J-2X engine, will carry the lunar lander to orbit to rendezvous with Orion and initiate the trans-lunar injection (TLI) burn that sends Orion and the lunar lander toward the Moon. When Orion and the lander arrive in lunar orbit, the crew will transfer to the lunar lander, which will transport them to and from the Moon's surface while the Orion vehicle remains in orbit. After completing their mission, the astronauts will return to the Orion crew module for the return trip to Earth.

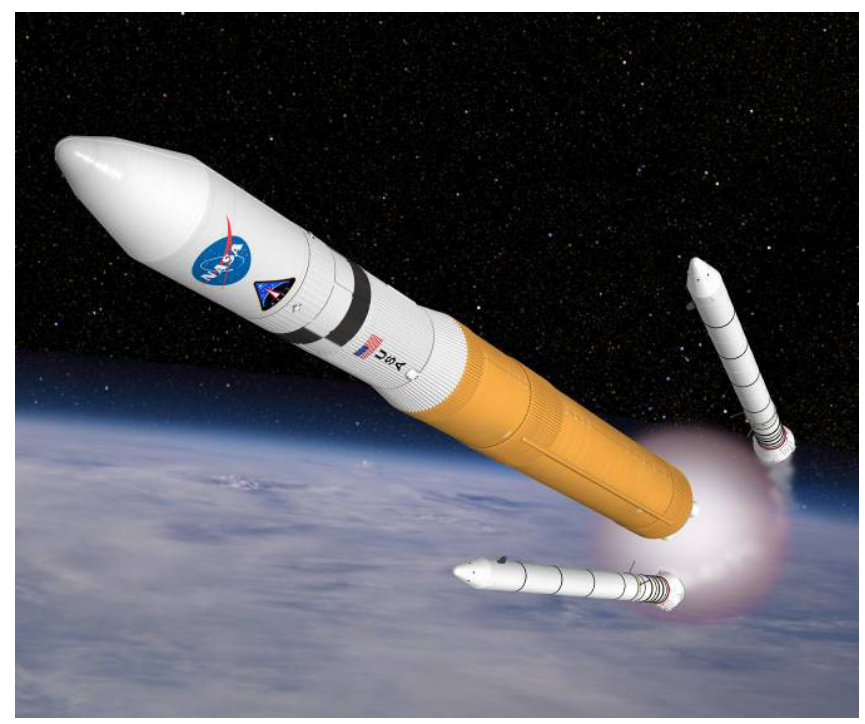

Figure 2 - Ares V Cargo Launch Vehicle.

In the Ares I Project's inaugural year, extensive trade studies and evaluations were conducted to improve upon the designs initially recommended by the ESAS, resulting in significant reduction of near-term and long-range technical and programmatic risks; conceptual designs were analyzed for fitness against requirements; and the contractual framework was assembled to enable a development effort unparalleled in American space flight since the Space Shuttle.

The Ares Projects Office (APO) completed the Ares I System Requirements Review (SRR) at the end of 2006the first such engineering milestone for a human-rated space transportation system in over 30 years. The team then completed a System Definition Review (SDR) in October 2007. With well-defined requirements for vehicle and mission performance, and with a system architecture in place, the project team now turns its focus to the Preliminary Design Review, scheduled for summer 2008. Taking into consideration the findings of the SRR and SDR, the design of the Ares I is being successively refined to meet the safety, operability, reliability, and affordability goals outlined by the Constellation Program.
Currently, the APO - a nationwide Government and industry partnership managed from NASA's Marshall Space Flight Center - is testing engine components, performing wind tunnel tests, and building hardware for the Ares I-X flight test mission. The heavy-lift Ares $\mathrm{V}$ is in the early design stage, with most activities focused on requirements validation and development of a cargo system that has synergistic hardware commonality between it and the Ares I. This can reduce the operational footprint and foster sustained exploration in the decades ahead.

With the nation's strategic goal of returning humans to the Moon for scientific exploration and preparing to place astronauts on Mars, APO has analyzed its business practices extensively to adapt them to the current design phase. For example, APO is dedicated to fostering a learning culture and implementing lean processes in the design stage to create a streamlined manufacturing and operations phase. These activities will allow the Agency to spend more of its limited resources on the scientific exploration that launch vehicles empower. The fundamental goal is to dramatically reduce the cost of owning and operating the Agency's nextgeneration space fleet, as directed in the Constellation Program's Architecture Requirements Document [3]. This paper will describe some of those business practices and the progress being made toward accomplishing that mission.

\section{TeChNiCal Progress}

\section{Trade Studies and Evaluations}

The ESAS provided the genesis for the Ares launch vehicles, narrowing down literally hundreds of possible vehicle configurations to six or seven, as seen in Tables 1 and 2. Nonetheless, this was just the beginning of the systems engineering trade studies affecting the requirements for a long-term, sustainable exploration strategy.

After examining the costs of modifying the Space Shuttle Main Engine (SSME) to allow it to restart in orbit, the Ares team determined that it was less difficult and less expensive to use an upgraded version of the J-2 upper stage engine from the Saturn V S-II and S-IVB stages, called the J-2X [4]. Because of the power difference between the SSME and the J-2X, the Ares I went to a five-segment Reusable Solid Rocket Booster (RSRB) for the first stage [5]. This change was additionally advantageous because the ESAS recommended using an advanced version of the J-2 for the Earth departure stage and two five-segment RSRBs for the Ares V. To simultaneously facilitate development, be cost effective, and meet the necessary payload requirements, the five SSMEs on the Ares V core stage were replaced with five commercial RS-68 engines from the Delta IV Evolved Expendable Launch Vehicle (EELV) program. These changes effectively reduced technical, schedule, and financial risks by reducing the number of propulsion systems as well as the amount of new development work that needed to be done. 
Table 1. Crew launch vehicle concepts investigated during ESAS. The highlighted column indicates the configuration that most closely resembles the current Ares I. The ESAS study originally recommended the 4-Segment RSRB with 1 SSME.

\begin{tabular}{|c|c|c|c|c|c|c|c|}
\hline $\begin{array}{r}\text { Feet } \\
300 \\
200 \\
100\end{array}$ & . & $A=$ & t. & E & E & F & F \\
\hline & $\begin{array}{c}\text { Human-Rated } \\
\text { Atlas V/New } \\
\text { Upper Stage } \\
\text { (US) }\end{array}$ & $\begin{array}{c}\text { Human-Rated } \\
\text { Delta IV/New } \\
\text { US } \\
\end{array}$ & $\begin{array}{c}\text { Atlas Phase } 2 \\
\text { (5.4-meter (m) } \\
\text { Core) }\end{array}$ & $\begin{array}{c}\text { Atlas Phase } \\
\text { X (8-m Core) }\end{array}$ & $\begin{array}{c}4 \text { Segment } \\
\text { RSRB with } \\
1 \text { SSME }\end{array}$ & $\begin{array}{c}5 \text { Segment } \\
\text { RSRB with } \\
1 \mathrm{~J}-2 \mathrm{~S} \\
\end{array}$ & $\begin{array}{c}5 \text { Segment } \\
\text { RSRB with } \\
4 \text { LR-85 }\end{array}$ \\
\hline $\begin{array}{c}\text { Payload } \\
\text { (lunar) }\end{array}$ & $\begin{array}{c}30 \text { metric tons } \\
(\mathrm{mT})\end{array}$ & $28 \mathrm{mT}$ & $26 \mathrm{mT}$ & $70 \mathrm{mT}$ & $25 \mathrm{mT}$ & $26 \mathrm{mT}$ & $27 \mathrm{mT}$ \\
\hline $\begin{array}{l}\text { Payload } \\
\text { (ISS) }\end{array}$ & $27 \mathrm{mT}$ & $23 \mathrm{mT}$ & $25 \mathrm{mT}$ & $67 \mathrm{mT}$ & $23 \mathrm{mT}$ & $24 \mathrm{mT}$ & $25 \mathrm{mT}$ \\
\hline $\begin{array}{c}\text { Loss of } \\
\text { Mission } \\
\text { (LOM) }\end{array}$ & $\begin{array}{c}\text { Mean } \\
\text { Probability: } \\
1 \text { in } 149\end{array}$ & 1 in 172 & 1 in 134 & 1 in 79 & 1 in 460 & 1 in 433 & 1 in 182 \\
\hline $\begin{array}{c}\text { Loss of Crew } \\
\text { (LOC) }\end{array}$ & 1 in 957 & 1 in 1,100 & 1 in 939 & 1 in 614 & 1 in 2,021 & 1 in 1,918 & 1 in 1,429 \\
\hline
\end{tabular}

Table 2. Cargo Launch Vehicle concept comparisons. The highlighted column depicts the "1.5 launch" concept that most closely resembles the current launch architecture. As noted for Table 1, the ESAS originally recommended using a four-segment RSRB for the crew launch vehicle.

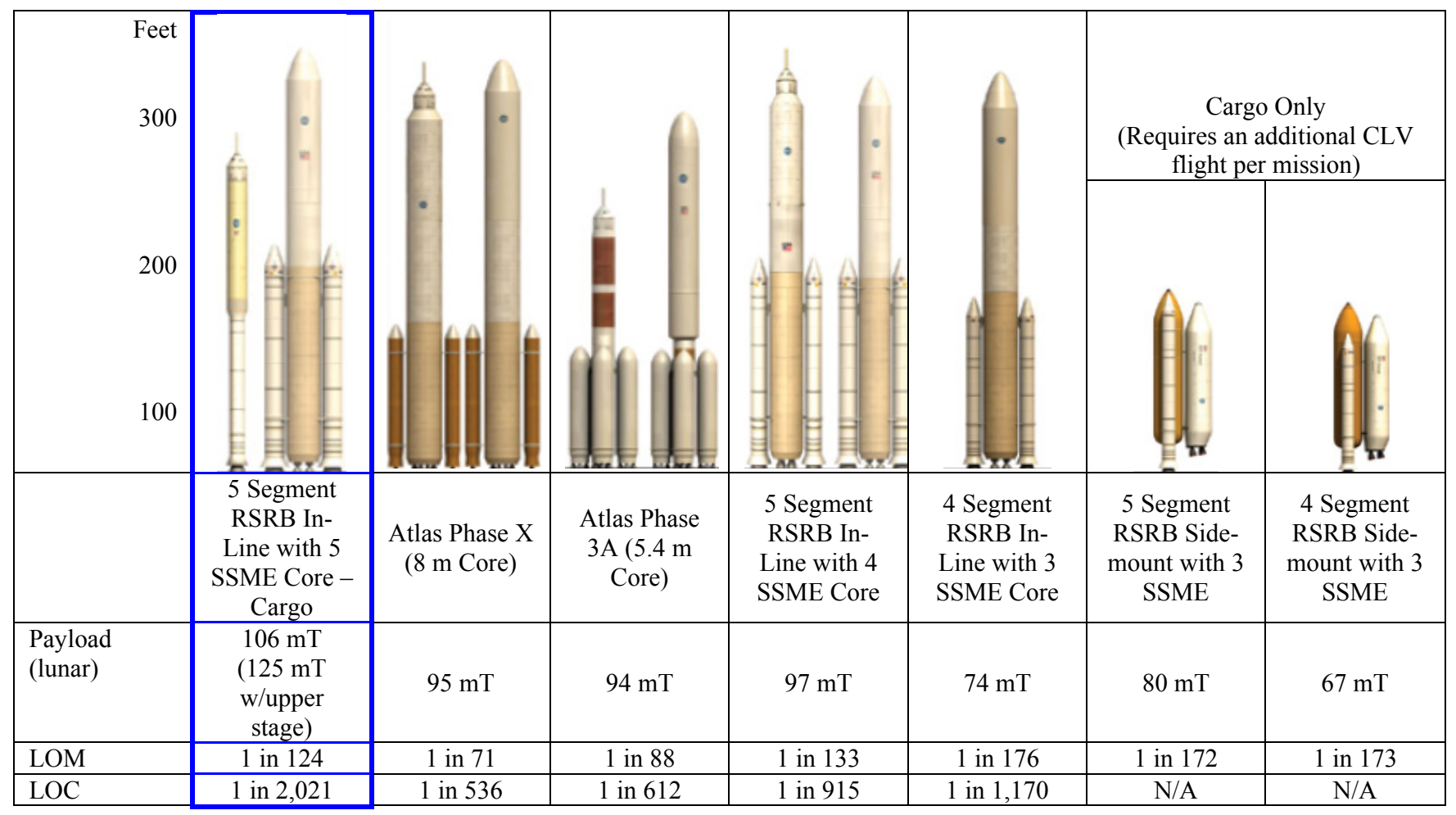




\section{Testing Strategy}

NASA has learned through experience that it can reduce operating costs through early, incremental, and thorough testing of its launch vehicles. This "test as you fly" strategy incorporates best practices from systems engineering as well as lessons learned. To fly humans safely aboard a launch vehicle requires a variety of methodologies to reduce technical, schedule, and cost risks.

Like the Apollo-Saturn program, the Ares launch vehicles will undergo a series of development, verification, and orbital flight tests as well as static ground tests before the first humans are sent into orbit for Constellation (Ares/Orion) missions in 2013 and regular missions to the International Space Station (ISS) in 2015.

Ares V will begin testing in 2018, with the first lunar mission slated for the 2020 timeframe.

The first Ares I flight test, Ares I-X, will occur in April 2009 and will test NASA's ability to control a vehicle with a similar size and shape, as shown in Figure 3.

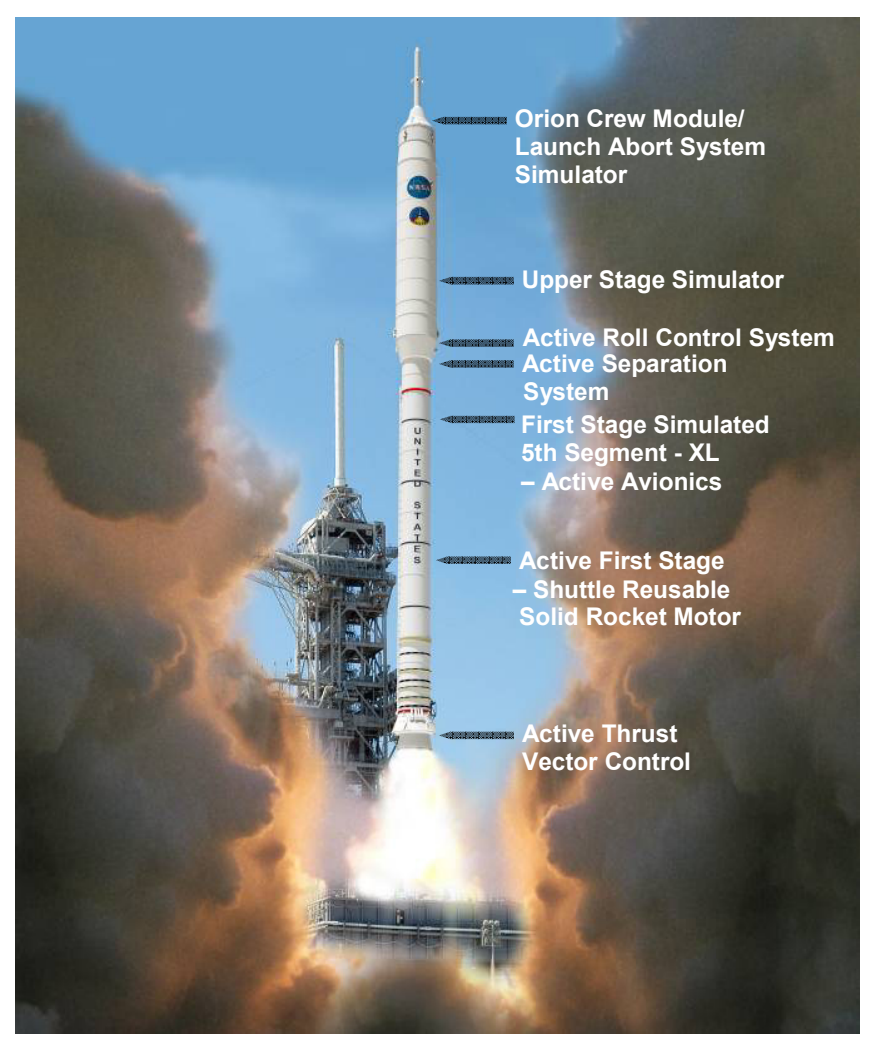

Figure 3 - Ares I-X flight test vehicle elements.

The Ares I-X mission will be a suborbital development flight test. It will give APO its first opportunity to gather critical data about the flight dynamics of the integrated launch vehicle stack, understand how to control its roll during flight, better characterize the severe stage separation environments the upper stage engine will experience during future flights, and demonstrate the first stage recovery system. As the agency makes the transition from the Shuttle to the Constellation Program, NASA will begin to modify the launch infrastructure and develop procedures for Ares ground and mission operations. The flight manifest includes two suborbital demonstrations, which will be supplemented by at least two orbital verification tests and one automated mission flight before the first crewed flight to ISS in 2015 .

The Ares I-X flight test vehicle will incorporate a mix of flight and mockup hardware, reflecting a configuration similar in mass and weight to the operational vehicle. It will be powered by a four-segment reusable solid rocket booster (RSRB) currently in Shuttle inventory, and will be modified to include a fifth, inert segment that makes it approximately the same size and weight as the five-segment RSRB. The Ares I-X flight profile will closely approximate the flight conditions that the Ares I will experience through Mach 4.5, at an altitude of about 130,000 feet and through maximum dynamic pressure ("Max Q"), which is approximately 800 pounds per square foot. To maintain a constant attitude throughout flight, the vehicle will include an active Roll Control System (RoCS), which also will measure the amount of roll torque generated during flight. The flight will aid the timing of first stage burnout, first stage separation, and upper stage ignition, which should occur around 130 seconds into flight.

With a launch date in April 2009, Ares I-X is on a successoriented development and production schedule. The Ares I$\mathrm{X}$ Mission Management Office has already conducted a Preliminary Design Review (PDR) and has a Critical Design Review (CDR) scheduled for February 2008. Due to the imminence of the flight, some elements of the Ares I-X Flight Test Vehicle (FTV) are already being fabricated.

First Stage-Because the Ares I-X team has access to a RSRB already in the Shuttle inventory, it can concentrate on developing the new forward structures that will be needed to connect the first stage to the simulated upper stage. These structures - the inert fifth segment, forward skirt, forward skirt extension, frustum, and interstage - will include new avionics, new parachutes, the Roll Control System (RoCS), and the first stage separation system.

Fabrication of the forward structures is already under way; these will be "battleship" models, which are manufactured to be stronger than they need to be to test for durability. The additional structural weight, which is also a concern on the Ares I operational vehicle, has caused the team to move the booster deceleration motors (BDMs) from the interstage to the aft skirt. This change ensures that the motor will pull away from the upper stage without recontacting or damaging the upper stage engine on future flights.

Recovery System-The drogue parachutes and main parachutes, which are much larger than the parachutes used for the Space Shuttle RSRBs, have been drop-tested successfully at Yuma Proving Grounds. These parachutes must be larger and stronger to accommodate the much larger 
and heavier booster.

RoCS-The RoCS, which will help the vehicle maintain a constant attitude during flight, will consist of two engines originally used on Peacekeeper missiles. These engines have been duty cycle tested at White Sands Test Facility to ensure that they can handle the anticipated operational cycle on Ares I-X, as seen in Figure 4. Additional engines will be sent to Kennedy Space Center (KSC) to test tanking and detanking procedures for hypergolic propellants (monomethyl hydrazine and nitrogen tetroxide). The RoCS CDR will occur in December 2007.

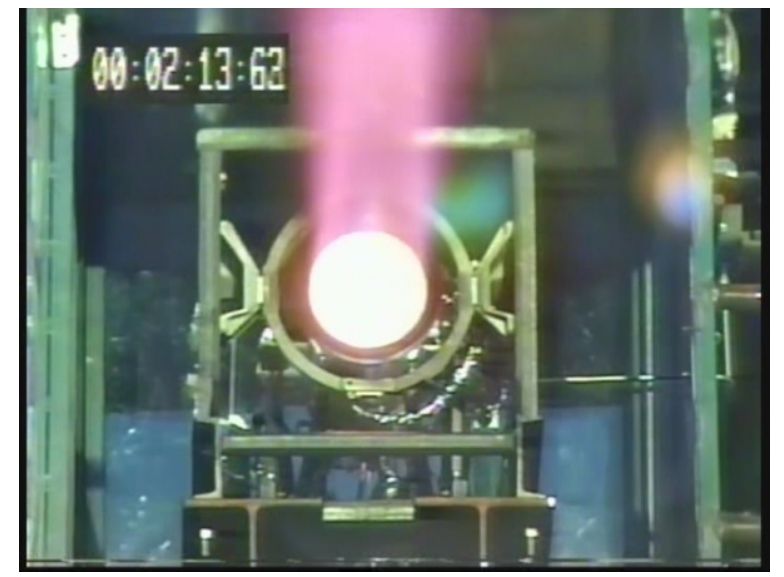

Figure 4-A Peacekeeper Axial Engine is tested for use on the Ares I-X test flight.

Upper Stage Simulator-Glenn Research Center (GRC) has the job of building the Upper Stage Simulator (USS) for Ares I-X. Because of limited work space and the need to transport the USS by barge from Ohio to KSC, the USS is being built in a series of 11 "tuna can" segments, which will be stacked on top of each other to make the final USS at $\mathrm{KSC}$ for final integration. Ares I-X is much taller than the Space Shuttle; however, because Launch Complex 39B will be used for launch-on-demand to support the Hubble Space Telescope servicing mission, there will not be time to modify the launch pad for Ares hardware. Therefore, the tuna-can segments will each include stairwells and interior work platforms to assure crew access to avionics and other internal hardware. GRC performed a stacking demonstration of its two pathfinder segments in September 2007. Flight hardware began construction in October 2007.

\section{Ares I Hardware Testing}

In addition to work being done on Ares I-X, ground testing of components continues on the operational ("mainline") Ares I crew launch vehicle. The element on the critical path for Ares development is the J-2X Upper Stage Engine. Other work has included construction of a new J-2X test stand at Stennis Space Center; refinements and wind tunnel testing of Ares Launch Abort System; and trade studies and fabrication for new hardware for the Ares I five-segment RSRB.
J-2X Upper Stage Engine-The Upper Stage Engine element team has assembled a powerpack version of the J$2 \mathrm{X}$, which is to begin testing on the A-1 Test Stand at SSC in November 2007, as shown in Figure 5. The actual J-2X powerpack - the main power-generating and pumping components of the engine - will consist of a gas generator, turbopumps, valves, and connecting feed lines and ducts. The turbopumps will pressurize liquid hydrogen fuel and liquid oxygen to characterize the legacy $\mathrm{J}-2 \mathrm{~S}$ turbopump and inlet duct design performance as a starting point for making modifications needed for the $\mathrm{J}-2 \mathrm{X}$ engine. The gas generator will drive the fuel and oxidizer turbopumps. Test stand lines, ducts, and valves will provide simulated inlet and outlet conditions that would be present on the pumps during a full-up engine hot-fire test.

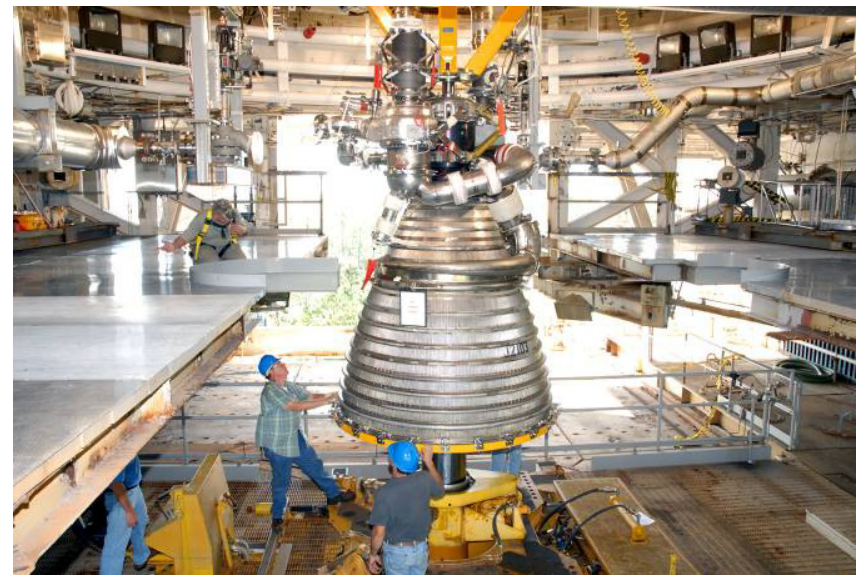

Figure 5 - The J-2X Powerpack is prepared for testing at Stennis Space Center.

In addition to the sea-level testing being performed at A-1, the new A-3 test stand, shown in Figure 6, will provide an environment to test the $\mathrm{J}-2 \mathrm{X}$ at higher simulated altitudes. The A-3 stand will be placed close to SSC's channel for easy access to barges bound for the Michoud Assembly Facility and KSC. Groundbreaking began in August 2007 and construction is already underway; the stand is due to be active by 2010 .

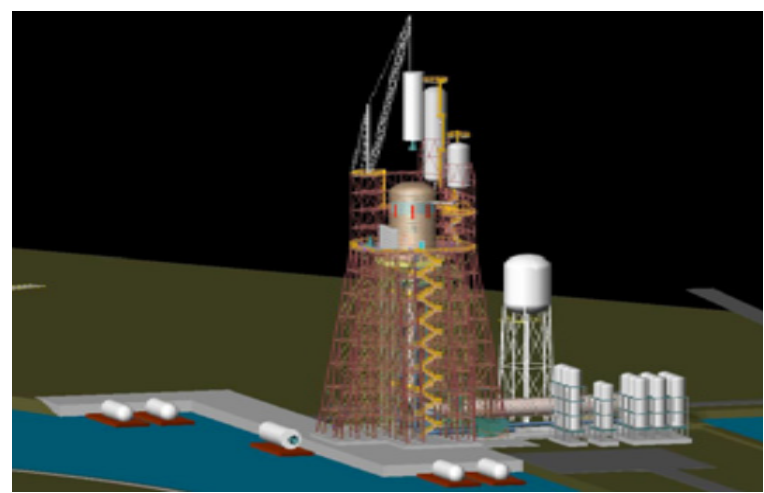

Figure 6 - The altitude-simulating A-3 Test Stand will stand over 200 feet tall and have easy access to the Gulf of Mexico. 
Ares Launch Abort System (ALAS) - The Ares I crew launch vehicle has undergone over 4,000 hours' worth of wind tunnel tests to verify the safety and performance of the outer mold line (OML) of the ALAS and other structures, including aerodynamic shapes and protuberances.

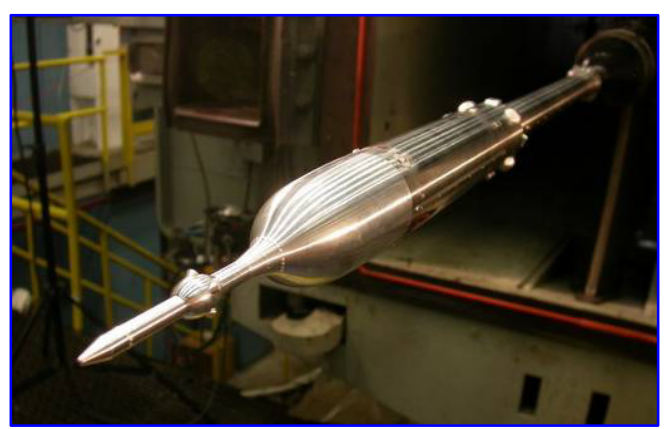

Figure 7 - A variety of ALAS designs are being tested in wind tunnels to define and minimize aerodynamic loads on the Orion crew module.

\section{Programmatic Progress}

\section{Project Reviews}

Ares I completed its System Requirements Review (SRR) in late 2006. The SRR helped finalize the overall functionality of Ares I, based on requirements flowed down from the Constellation Program. This review ensured that Ares I's capabilities would match the needs of the Orion crew exploration vehicle. The System Definition Review (SDR), which kicked off in September 2007 and is scheduled to be completed in October 2007, will take an overall look at how Ares I should be engineered to meet the tasks established in the SRR. From SRR, the APO will begin work on the vehicle Preliminary Design Review (PDR) in 2008, which will ensure that the design anticipated by the SDR will meet the final mission needs. Ares I's Critical Design Review (CDR) will not occur until 2009 and will incorporate lessons learned from the Ares I-X flight test.

So far, the Ares I vehicle design and development is progressing on schedule. There have been few surprises or major design challenges arising from the various reviews. The reviews are still proceeding at a pace that will support an initial operating capability no later than 2015 .

\section{Incorporating Best Practices}

While making steady technical progress, APO is also concerned about improving its business processes by incorporating best practices from private industry. One of Ares' primary performance metrics is to substantially reduce the per-flight cost of space operations, enabling the agency to concentrate more of its resources on exploration. In addition to this goal, the agency seeks to become a better steward of taxpayer dollars. Among the tools APO is using to manage Ares are team and meeting norms, Earned Value Management (EVM), and Lean Six Sigma.

Team and Meeting Norms-A common and often neglected management practice is setting behavioral expectations and norms. Especially in light of the Columbia Accident Investigation Board (CAIB) Report, which criticized the agency for its internal culture [6], the Ares team made a conscious effort to establish team norms up front. These norms include teamwork, integrity, constant communication, constructive feedback, and accountability.

Accompanying these team norms are meeting norms, including starting and ending on time, having a reasonable agenda, and valuing the impact of all attendees. These behaviors were established to ensure that managers and other teammates use their time effectively and positively.

Earned Value Management-NASA has been one of the government agencies to pioneer the use of EVM to track its costs, schedules, and technical milestones. By tracking budget, actual costs, and work completed over time, APO has been able to monitor contractor performance as well as address cost and schedule problems before they become serious concerns.

Lean Thinking - The Constellation Program was designed to return human beings to the Moon in preparation for the first human footprints on Mars - and to do so within NASA's existing budget. This program philosophy demands reduced costs to enable NASA to spend less money on human spaceflight operations and more on actual exploration activities. To meet this live-within-its-means objective, the Agency is instituting industry best practices like Lean Manufacturing in an effort to reduce costs and increase efficiency in the post-Shuttle era.

"Lean" processes emphasize reducing the overall cost of doing business and improving the value stream [7]. APO has been applying Lean thinking to many of its activities, including the Ares I-X flight test.

In late April and early May 2007, managers from across the Agency met at Langley Research Center (LaRC) to discuss how to implement Lean processes to the Ares I-X test flight. The need for a Lean effort was identified, in part, because different levels of the Ares I-X organization had conflicting notions about what level of safety to apply to a one-time uncrewed test of a prototype Ares I vehicle. As a result of this meeting, the various elements performing Ares I-X activities were unified under one Mission Manager reporting to the Constellation Program (CxP) Office, thereby reducing the amount of bureaucracy. Further, to reduce decisionmaking and approval times, the Ares I-X Mission will reduce its number of independent review boards from 10 to 4. These organizational changes are necessary if Ares I-X is going to react quickly and achieve its April 2009 launch date. 
Following the decision to establish the Ares I-X MMO, the team held a series of meetings to apply the Lean philosophy to their hardware development processes. The goal of this "leaner" effort was to incorporate 60 calendar days of additional margin into the overall flight test schedule. The effort was successful in that most development plans have 60 days of schedule margin.

When all of these events were completed, each of the elements was able to restructure its processes to meet a 60 day schedule shift to the left. The Ares I-X team is now in the process of implementing the changes recommended in the Lean events and re-baselining the schedule to match the new plans.

Lean events have also been conducted for the mainline Ares vehicle. Some sample results include:

- Streamlining boards/panels approval process: reduced from 5 to 2 the number of board approval steps within Ares.

- Design reviews process: $39 \%$ reduction in time to conduct design reviews.

- Time for risk approval: $66 \%$ reduction in the time to evaluate and approve a candidate risk through the risk management system.

- Trade studies: $50 \%$ reduction in the number of steps to conduct formal trade studies - from idea to decision.

- Task description sheet (TDS) development for ADAC cycles: from $3 \%$ to $80 \%$ automation.

Results like these ensure that less time is spent on waste and more time is applied toward value-added work.

\section{CONCLUSION}

This is an exciting time to be at NASA. As the agency transitions from one generation of space hardware to the next, we face an ambitious amount of work. While finishing the ISS and winding down the Space Shuttle operations, we are also designing and building an entirely new space exploration architecture for not much more than NASA's previous budget. The work we are doing today and will do tomorrow promises to be exciting for the agency and for the nation as a whole. The Ares I crew launch vehicle will assure long-term human-rated access to space, while the Ares V cargo launch vehicle will allow the agency to establish a permanent outpost on the Moon as well as loft larger payloads for other missions, such as space-based telescopes and planetary orbiters and rovers for more capable missions of discovery, As we move closer to once again placing human footprints on the Moon, we will continue to require our nation's best and brightest individuals to design the tools and technologies we will need to achieve this bold mission. And, as always, we will be looking for ways to apply the things we learn and the things we do to Earth-based concerns. For instance, the U.S. strategy to scientifically explore space will fuel innovations such as solar power and water recycling, as well as yield new knowledge that directly benefits life on Earth. Ares I and $\mathrm{V}$ are keys to opening the space frontier for further and greater peaceful endeavors.

\section{REFERENCES}

[1] National Aeronautics and Space Administration. Exploration Systems Architecture Study, Final Report, November 2005.

[2] National Aeronautics and Space Administration. The Global Exploration Strategy: the Framework for Coordination. May 2007.

[3] National Aeronautics and Space Administration. Constellation Architecture Requirements Document, CxP70000. July 2006.

[4] Jim Snoddy. "Development of the J-2X Engine for the Ares I Crew Launch Vehicle and the Ares V Cargo Launch Vehicle: Building on the Apollo Program for Lunar Return Missions.” International Astronautical Congress 2006.

[5] Alex S. Priskos and Thomas J. Williams. "Developing Primary Propulsion for the Ares I Crew Launch Vehicle and Ares V Cargo Launch Vehicle.” 2007 AIAA Joint Propulsion Conference.

[6] Columbia Accident Investigation Board. Report, Volume 1, p. 97.2003.

[7] James P. Womack and Daniel T. Jones. Lean Thinking: Banish Waste and Create Wealth in Your Corporation. New York: Simon \& Schuster, 1996.

\section{BIOGRAPHIES}

\section{Stephen Cook}

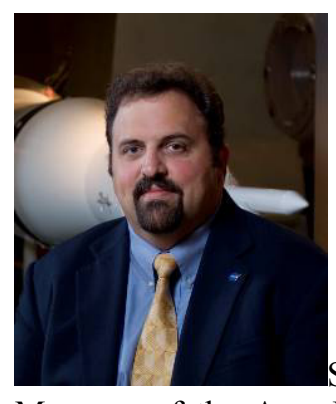
Manager of the Ares Projects Office at NASA's Marshall Space Flight Center in Huntsville, Alabama. Named to the position in September 2005, Mr. Cook is responsible for directing a team of over 1,300 Government and contractor employees in the design, development, vehicle integration, and testing for the Ares I crew launch vehicle and Ares V cargo launch vehicle. Fulfilling the strategic goals outlined 
in the Global Exploration Strategy, these safe, reliable, and affordable space transportation solutions will enable Americans to build an outpost on the Moon to prepare for much longer journeys to Mars.

Prior to establishing the Ares team, Mr. Cook held a variety of NASA leadership positions, including Deputy Manager of the Next Generation Launch Technology and Manager of the Advanced Space Transportation Program.

Mr. Cook, a member of the Government's Senior Executive Service, has received numerous awards, including a NASA Exceptional Service Medal in 2006 for his contributions to the Exploration Systems Architecture Study; the 2006 Toftoy Award from the American Institute of Aeronautics and Astronautics for outstanding technical management; and the NASA Outstanding Achievement Medal in 1999 for exceptional accomplishments in space transportation. He holds a bachelor's degree in aerospace engineering and mechanics from the University of Minnesota.

\section{Teresa Vanhooser}

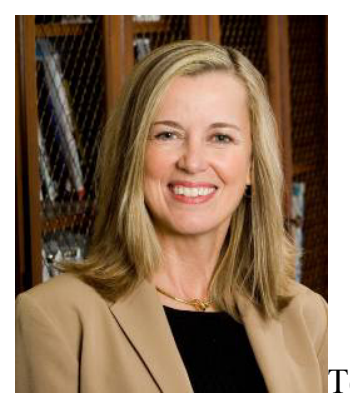

of the Ares Projects Flight Center in Huntsville, Alabama.

Named to the position in May 2007, Ms. Vanhooser is responsible for assisting the manager in overall project management of NASA's Ares I crew launch vehicle, which will transport the Orion crew exploration vehicle to space and deliver small, uncrewed cargo payloads to space - key to the Vision for Space Exploration. The office is responsible for overall integration of the launch vehicle system, and development of a first stage derived from the current space shuttle booster and motor elements and a new upper stage powered by a J-2X main engine.

Previously, from August 2004 to May 2007, Ms. Vanhooser was co-deputy director of the Engineering Directorate at Marshall. She served as deputy director of the Flight Projects Directorate from May to August of 2004. She was responsible for project management, design, development, integration, testing and operations of ground and flight systems for the space station, along with overseeing operations of the Chandra X-ray Observatory - the world's most powerful X-ray telescope.
Ms. Vanhooser began her NASA career at Marshall in 1980 as an engineer in the Ground Systems Analysis Branch, where she was responsible for defining, developing and documenting requirements for integration and testing of payloads for the Spacelab carrier, used to conduct science experiments in the shuttle's payload bay.

Ms. Vanhooser earned a bachelor's degree in industrial engineering from Tennessee Technological University in 1980, and a master's in administrative science and project management from the University of Alabama in Huntsville in 1986 . 